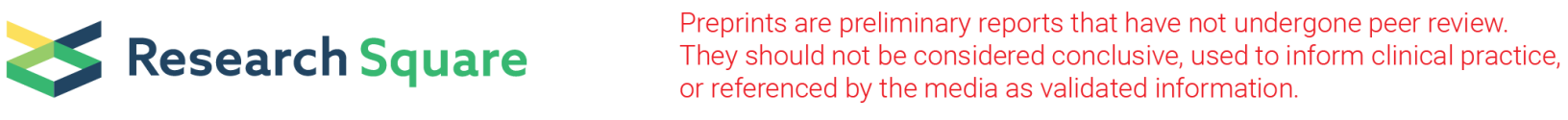

\title{
Effect of Different Selenium Precursors on Structural Characteristics and Chemical Composition of Cu2ZnSnSe4 Nanocrystals
}

Stanislav Igorovich Kakherskiy ( $\square$ s.kacherski@ekt.sumdu.edu.ua )

Sumy State University https://orcid.org/0000-0002-7594-0908

Roman Pshenychnyi

Sumy State University

Oleksandr Dobrozhan

Sumy State University

Jaroslav Vaziev

Shostka Institute

Anatoliy Opanasyuk

Sumy State University

Yuriy Gnatenko

Institute of Physics of National Academy of Sciences of Ukraine

\section{Research Article}

Keywords: Nanocrystals, Cu2ZnSnSe4, chemical composition, morphology, structure, XRD, FTIR

Posted Date: April 1st, 2021

DOl: https://doi.org/10.21203/rs.3.rs-334556/v1

License: (c) (i) This work is licensed under a Creative Commons Attribution 4.0 International License. Read Full License 


\section{Abstract}

In the presented work $\mathrm{Cu}_{2} \mathrm{ZnSnSe}_{4}$ nanocrystals have been synthesized by the polyol method. The chemical composition, morphological, structural, and microstructural properties of $\mathrm{Cu}_{2} \mathrm{ZnSnSe}_{4}$ nanocrystals depending on synthesis temperature and time as well as precursor composition have been thoroughly investigated using scanning and transmission electron microscopies, energy dispersive X-ray analysis, X-Ray diffraction, FTIR spectroscopy. We compared the properties of nanocrystals synthesized from different precursors containing selenourea or amorphous selenium as a source of selenium and then determined the optimal conditions for nanocrystals synthesis. It was found that the optimal synthesis time for nanocrystals obtained using the first approach was $t=(30-45) \mathrm{min}$, and for the second approach $t=120 \mathrm{~min}$. It was also found that the optimal composition for the synthesis of single-phase $\mathrm{Cu}_{2} \mathrm{ZnSnSe}_{4}$ nanocrystals by the second approach is the molar ratio of precursors 2:1.5:1:4 and synthesis temperature $\mathrm{T}=280^{\circ} \mathrm{C} . \mathrm{Cu}_{2} \mathrm{ZnSnSe}{ }_{4}$ nanocrystals synthesized under optimal conditions were used to develop nanoinks for printing solar cell absorbers by $2 D$ and $3 D$ printers.

\section{Introduction}

Up to date, research topics related to the development of electronic elements and devices using two- (2D) and three-dimensional (3D) printing techniques are developed rapidly. These techniques are affordable, versatile, economical, and waste-free that can significantly simplify the development manufacturing process and reduce production costs [1, 2, 3]. In addition, there is possibility to apply a wide range of substrates, including flexible, because such technologies are low-energy and do not require heating the substrates up to thermal degradation [4-10].

Simple inkjet printers, where standard inks can be replaced by nanoinks containing a suspension of metals or semiconductor's nanocrystals (NC), can be used for 2D printing of electronic elements and devices [11-13]. 3D printers allow us to print films on substrates of any shape, including human skin or clothing $[4,14-19]$.

2D and 3D printing technologies with nanoinks, based on metal NCs allow to develop printed circuit boards [20-21] and use different semiconductor compounds to design passive and active elements of electronic devices [22-29]. However, nowadays the scientific and technological challenge is to develop the synthesis procedure of semiconductor NCs with controlled properties and the development of the stable and environmentally friendly colloidal solutions with the required surface tension and viscosity which can be used as inks for printing processes [30-32].

The modern absorbers of solar cells (SC) contain multicomponent compounds such as $\mathrm{Cu}_{2} \mathrm{ZnSnS}_{4}, \mathrm{Cu}_{2} \mathrm{ZnSnSe}_{4}$ and $\mathrm{Cu}_{2} \mathrm{ZnSn}\left(\mathrm{S}_{\mathrm{x}} \mathrm{Se}_{1-\mathrm{x}}\right)_{4}$ [33-37]. The compounds possess close to optimal energy bandgap $\left(E_{g}\right)$, high light absorption coefficient $\left(\sim 10^{5}\right.$ $\mathrm{cm}^{-1}$ ), long lifetime, and high mobility of charge carriers [38]. The kesterite based compounds do not contain rare and environmentally hazardous components, in contrast, the elements are widespread in the Earth's crust and the cost of production is low [39-40]. However, today, certified laboratory SE's efficiency based on these materials does not exceed 10-11.3\% [41]. Note that absorbers of the most efficient SC ( $\eta=11.1 \%)$ were obtained by the vacuum-free method (using a solution based on hydrazine) [42]. However, hydrazine used as a solvent in such process is highly toxic, requires very careful handling and cannot be used in the mass production.

One of the reasons of the low efficiency of SC based on $\mathrm{Cu}_{2} \mathrm{ZnSnS}_{4}, \mathrm{Cu}_{2} \mathrm{ZnSnSe}_{4}, \mathrm{Cu}_{2} \mathrm{ZnSn}\left(\mathrm{S}_{\mathrm{x}} \mathrm{Se}_{1-\mathrm{x}}\right)_{4}$ layers is a narrow range of compound homogeneity which causes the appearance of large number of defects and secondary phases during the thin films growth, and, as a result, its low structural quality. Therefore, an effective strategy for obtaining thin films of kesterite compounds with controlled crystal structure and chemical composition, high degree of crystallinity, minimum content of secondary phases, is its processing in three stages: colloidal synthesis of single-phase NCs with the subsequent deposition of its suspension on substrates using non-vacuum methods, for example, spray methods, 2D or 3D printing techniques, and, finally, post-growth thermal annealing of the obtained samples to improve the structural properties $[33,43]$. As a result, the structural properties of the thin films, such as phase composition, lattice parameters, and size of coherent scattering regions (CSR), which play an important role in determining the functional characteristics of SCs, mainly depend on the conditions of NCs obtaining, and then the films, and their post-growth treatments. In such way in the research work [43] SCs with the efficiency of solar energy conversion $\eta=10.2 \%$ were obtained on the basis of $\mathrm{Cu}_{2} \mathrm{ZnSn}\left(\mathrm{S}_{x} \mathrm{Se}_{1-\mathrm{x}}\right)_{4}$ absorbers grown from initial $\mathrm{Cu}_{2} \mathrm{ZnSnSe}_{4} \mathrm{NCs}$. At the same time, $\left.\mathrm{Cu}_{2} \mathrm{ZnSn}_{(\mathrm{x}} \mathrm{Se}_{1-\mathrm{x}}\right)_{4}$ films are now 
mainly made from $\mathrm{Cu}_{2} \mathrm{ZnSnS}_{4}$ nanocrystals $[44,45]$, and not $\mathrm{Cu}_{2} \mathrm{ZnSnSe}_{4}$ because the $\mathrm{Cu}_{2} \mathrm{ZnSnS}_{4} \mathrm{NCs}$ are easier to obtain compared to $\mathrm{Cu}_{2} \mathrm{ZnSnSe}{ }_{4} \mathrm{NCs}$. At present, selenourea $\left(\mathrm{NH}_{2}\right)_{2} \mathrm{CSe}$ is mainly used as a source of selenium in the synthesis of $\mathrm{Cu}_{2} \mathrm{ZnSnS}_{4}$ and $\mathrm{Cu}_{2} \mathrm{ZnSnSe}_{4}$ nanocrystals [46-48]. Using precursors based on cheaper elemental selenium $\mathrm{Cu}_{2} \mathrm{ZnSnSe}_{4}, \mathrm{NCs}$ were obtained only by the solvothermal method [49,50], hydrothermal method [51], two-step hot-injection method [52-53], and solventthermal reflux technique [54-55].

Previously, we optimized the conditions to synthesize $\mathrm{Cu}_{2} \mathrm{ZnSnS}_{4}$ and $\mathrm{ZnO} \mathrm{NCs}$ using the polyol method [56-60]. As a result, we obtained single-phase nanocrystals of the kesterite (CZTS) and wurtzite (ZnO) phases with a controlled sizes. In this work, we optimized the process of $\mathrm{Cu}_{2} \mathrm{ZnSnSe}{ }_{4} \mathrm{NCs}$ synthesis using two different sources of selenium in the precursor: selenourea and elemental selenium and then we investigated the morphological, structural, and microstructural properties depending on the synthesis temperature, time, and precursors combination.

\section{Material And Methods}

$\mathrm{Cu}_{2} \mathrm{ZnSnSe}{ }_{4} \mathrm{NCs}$ were synthesized by the polyol method in the reaction media of diethylene glycol (DEG) and triethylene glycol (TEG) using two different selenium precursors. According to the first approach, initially, the solution of polyvinylpyrrolidone (PVP) in the mass ratio $1: 1$ to the finished product was prepared. Then, a mixture of salts $\mathrm{CuCl}_{2} \cdot 2 \mathrm{H}_{2} \mathrm{O}, \mathrm{Zn}\left(\mathrm{CH}_{3} \mathrm{COO}\right)_{2} \cdot 2 \mathrm{H}_{2} \mathrm{O}, \mathrm{SnCl}_{2} \cdot 2 \mathrm{H}_{2} \mathrm{O}$ in the different molar ratios $\mathrm{Cu}: \mathrm{Zn}$ was added to the resulting solution and stirred with magnetic stirrer heated to $65^{\circ} \mathrm{C}$ for $1 \mathrm{~h}$. The synthesis of the NCs at the temperature of the reaction medium was carried out separately with the exposure interval of $\tau=0,15,30$, $60 \mathrm{~min}$. The synthesis procedure more detail described in [57].

According to the second approach, a mixture of $\mathrm{CuCl}_{2} \cdot 2 \mathrm{H}_{2} \mathrm{O}, \mathrm{Zn}\left(\mathrm{CH}_{3} \mathrm{COO}\right)_{2} \cdot 2 \mathrm{H}_{2} \mathrm{O}$ and $\mathrm{SnCl}_{2} \cdot 2 \mathrm{H}_{2} \mathrm{O}$ salts as well as amorphous selenium, grounded in an agate mortar, were placed in a $50 \mathrm{ml}$ three-necked flask. Then, $12 \mathrm{ml}$ of TEG was added to that with subsequent heating as described in the first approach. In contrast to the first approach and literature review, where selenourea is used as a source of selenium, i.e. $\left(\mathrm{NH}_{2}\right)_{2} \mathrm{CSe}$ compound [61-63], the use of elemental selenium allowed us to significantly reduce the cost of synthesis of the final compound. After reaching a temperature of $120^{\circ} \mathrm{C}$, the air was pumped out of the flask and inert argon gas was charged. The mixture was kept at this temperature for $30 \mathrm{~min}$ and quickly heated to the synthesis temperatures $T=$ $220,240,250,260,270,280^{\circ} \mathrm{C}$ for $120 \mathrm{~min}$. In the process of $\mathrm{Cu}_{2} \mathrm{ZnSnSe}{ }_{4} \mathrm{NCs}$ synthesis, samples with an exposure interval $\tau=30$, 60,90 , and 120 min were obtained at the temperature of the reaction medium of $260^{\circ} \mathrm{C}$. The initial molar ratio of elements in the precursors used corresponded to the stoichiometric composition of the compound (2:1:1:4) and the amount of zinc was exceeded.

In the first and the second approaches, after syntheses, the mixture was cooled down to room temperature and the synthesized product was separated from the organic component (DEG, TEG) by centrifugation. Residues of polyol compounds were washed using ethanol with vigorous shaking followed by centrifugation. The washed $\mathrm{Cu}_{2} \mathrm{ZnSnSe}{ }_{4}$ samples were dried at $60^{\circ} \mathrm{C}$ for $12 \mathrm{~h}$.

X-ray diffractometer DRON 4-07 was used to determine the structural and microstructural properties of the synthesized NCs. The analysis was made in $\mathrm{Nifiltered} K_{a}$ radiation of a copper anode. The obtained diffractograms were normalized to the peak intensity (112) of the tetragonal phase of the $\mathrm{Cu}_{2} \mathrm{ZnSnSe}{ }_{4}$ compound. The phase analysis was performed by comparing the diffraction angles from the test samples and diffraction angles according to the reference data of JCPDS ( $\mathrm{Cu}_{2} \mathrm{ZnSnSe}{ }_{4}-$ № 00-052-0868 [64]).

All profile lines were processed to the following procedures: background extraction, emission smoothing, separation $K_{a}$ double that were performed using standard diffractometer software.

The lattice parameters $a$ and $c$ of the tetragonal unit cell were calculated using the following equations [65-66]:

$$
a_{C Z T S}=\frac{\lambda}{2 \cdot \sin \theta} \sqrt{h^{2}+k^{2}+l^{2}\left(\frac{a}{c}\right)^{2}}, c_{C Z T S}=\frac{l}{\sqrt{-\frac{h^{2}+k^{2}}{a^{2}}+\left(\frac{2 \cdot \sin \theta}{\lambda}\right)^{2}}},
$$

where $2 \theta$ is Bragg angle; $\lambda$ is the wavelength of $\mathrm{X}$-ray radiation; $(h k l)$ are Miller indices. The reflection from the crystallographic plane (112) was used for the calculations. The unit volume of materials was calculated using formula 


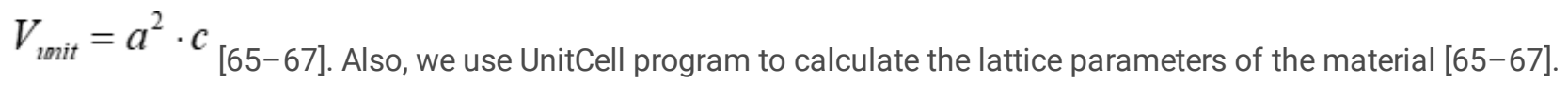

The average size of CSR and the level of microdeformations $(\varepsilon)$ in the obtained samples were calculated by the physical broadening of the diffraction peaks (112), (204), (312) using the following equations [65-68]:

$$
L=\frac{0.94 \cdot \lambda}{\beta \cdot \cos \theta}, \quad \varepsilon=\frac{\beta \cdot \cos \theta}{4}
$$

where $\lambda$ is the wavelength; $\beta$ is the value of the physical expansion of the corresponding diffraction maximum; $\theta$ is the diffraction angle.

The morphological properties of the synthesized NCs were studied using a transmission electron microscope TEM-125K. The study of NCs elemental composition was performed using a scanning electron microscope SEO-SEM Inspect S50-B, which is equipped with an energy-dispersive spectrometer AZtecOne with X-MaxN20 detector (Oxford Instruments plc).

The methodology for studying the structural, microstructural, chemical properties of the nanoparticulate products is described in detail in our previous works $[57,59,66-68]$.

\section{Results And Discussion}

The electron microscopic images of $\mathrm{Cu}_{2} \mathrm{ZnSnSe}_{4} \mathrm{NCs}$ synthesized at the different growth times using the first and second approaches are shown in Fig. 1. It was found that, the NCs average size synthesized by the first method increased from (5.0 \pm 3.0 ) $\mathrm{nm}(\tau=30 \mathrm{~min})$ to $(12.0 \pm 3.0) \mathrm{nm}(\tau .=60 \mathrm{~min})$. NCs sizes obtained by the second method was two to three times larger than obtained by the first method. The crystals showed different shapes, from quasi-spherical to pyramidal forms. During the synthesis process, NCs collected in conglomerates which sizes (50-80) nm (Fig. 1).

To determine the optimal conditions for the obtained NCs, we investigated the dependence of the phase composition on temperature, synthesis time and precursor composition. Figure 2 presents diffractograms from NCs, in the synthesis of which the $\left(\mathrm{NH}_{2}\right)_{2} \mathrm{CSe}$ compound was used (first approach). The particles were obtained during the synthesis time from 0 to 60 min. Diffraction patterns from NCs show reflection peaks at the $(27.25-27.30)^{\circ},(45.30-45.35)^{\circ},(53.60-53.65)^{\circ},(65.85-66.40)^{\circ}$, and $(72.65-72.75)^{\circ}$, which correspond to the reflections from (112), (204), (116), (008) and (413) crystallographic planes of the $\mathrm{Cu}_{2} \mathrm{ZnSnSe}_{4}$ compound of the tetragonal phase. The secondary phases in the material were not detected using the XRD method, because its concentration did not exceed the detectable ability of the method (3-5\% by weight) [69]. Diffractograms of $\mathrm{Cu}_{2} \mathrm{ZnSnSe}_{4} \mathrm{NCs}$ synthesized using the first approach were characterized by the following features: with increasing synthesis time, the intensity of diffraction peaks increased significantly (for example, for the plane (112) and synthesis time 0 and $60 \mathrm{~min}$, this value increased doubled), and their half-width decreased.

In the case of syntheses using elemental selenium (the second approach), the exposure interval of the reaction medium at different temperatures was $120 \mathrm{~min}$. The initial molar ratio of the precursors used corresponded to the stoichiometric composition of the compound and was $\mathrm{CuCl}_{2}: \mathrm{Zn}\left(\mathrm{CH}_{3} \mathrm{COO}\right)_{2}: \mathrm{SnCl}_{2}: \mathrm{Se}=2: 1: 1: 4$. Diffractograms obtained from the synthesized NCs are shown in Fig. 3a.

As can be seen, at a synthesis temperature of $220^{\circ} \mathrm{C}$ the diffraction patterns from the NCs shows a large number of lines, indicating that there is a mixture of different phases (curve 1). According to [69], in the case of zinc-depleted material, the $\mathrm{Cu}_{2} \mathrm{SnSe}_{3}$, $\mathrm{Cu}_{2} \mathrm{ZnSn}_{3} \mathrm{Se}_{8}, \mathrm{Cu}_{2} \mathrm{Se}$ and $\mathrm{Cu}_{4} \mathrm{SnS}_{4}$ compounds can be formed. These compounds are characterized by the existence of several polymorphic modifications. But the main feature that complicates a more accurate interpretation of the results of $\mathrm{X}$-ray phase analysis is that these phases have spectra very similar to the diffraction spectra of the $\mathrm{Cu}_{2} \mathrm{ZnSnSe}_{4}$ compound of the tetragonal phase [70-73].

It is established that with increasing synthesis temperature the number of peaks in the diffraction patterns decreases (curves 2-3) and at temperatures $T \geq 260^{\circ} \mathrm{C}$ in the reaction medium, a product or mixture of products with almost the same position of peaks and their intensity ratio (curves 4-6) were formed. 
Diffractograms of the substance synthesized at $T \geq 260^{\circ} \mathrm{C}$ show the reflection peaks at $(27.05-27.30)^{\circ},(45.00-45.25)^{\circ},(53.30-$ $53.60)^{\circ},(65.60-65.90)^{\circ},(72.35-72.70)^{\circ}$, corresponding to the reflections from (112), (204), (116), (008) and (413) crystallographic planes of $\mathrm{Cu}_{2} \mathrm{ZnSnSe} e_{4}$ compound. Secondary phases in the material were not detected by diffractometric method.

To determine the optimal conditions for the synthesis of NCs at a temperature of $260{ }^{\circ} \mathrm{C}$, when material single-phase was formed, samples were taken at the different exposure times of the reaction mixture. The corresponding diffractograms from the samples synthesized over time $\tau=30,60,90$, and 120 min are shown in Fig. 3b. The results obtained indicate that optimal interval of NCs synthesis was 120 min (curve 4).

To determine the chemical composition of the obtained material, its chemical analysis was performed using the EDX method. It is known that the theoretical atomic ratio of the components of the $\mathrm{Cu}_{2} \mathrm{ZnSnSe}_{4}$ compound must be $C_{C u}: C_{Z n}: C_{S n}: C_{S e}=25.0: 12.5$ : $12.5: 50.0$ (Table 1). Accordingly, the content of the components of the compound in the precursor was selected. However, determining the composition of the obtained samples indicates that the entry of different elements into the NCs occurs at different speeds. So, at the synthesis temperature $T=260^{\circ} \mathrm{C}$ and the time of $30 \mathrm{~min}$ zinc atoms are not embedded from the reaction medium into the compound (Table 1). In this case, the CuSe and $\mathrm{Cu}_{2} \mathrm{SnSe}_{3}$ phases are formed in the sediment in a ratio of 2:1, which is confirmed by X-ray diffractometry data. With increasing growth time of NCs to $120 \mathrm{~min}$, the zinc content in the synthesized product increases to 2 at.\%.

Table 1

Elementary composition of $\mathrm{Cu}_{2} \mathrm{ZnSnSe}{ }_{4} \mathrm{NCs}$ obtained by $2 \mathrm{nd}$ approach from precursors at the different composition under alteration of the synthesis conditions

\begin{tabular}{|c|c|c|c|c|c|c|c|}
\hline \multicolumn{3}{|c|}{ Samples } & \multicolumn{3}{|c|}{ Atomic percentage, C } & \multicolumn{2}{|l|}{ Relation } \\
\hline$T^{\circ} \mathrm{C}$ & $\tau, \min$ & $\mathrm{C}_{\mathrm{Cu}}$ & $\mathrm{C}_{\mathrm{Zn}}$ & $\mathrm{C}_{\mathrm{Sn}}$ & $\mathrm{C}_{\mathrm{Se}}$ & $\mathrm{C}_{\mathrm{Cu}} / \mathrm{C}_{(\mathrm{Zn}+\mathrm{Sn})}$ & $\mathrm{C}_{\mathrm{Zn}} / \mathrm{C}_{\mathrm{Sn}}$ \\
\hline \multicolumn{8}{|c|}{$\mathrm{Cu}_{2} \mathrm{ZnSnSe}{ }_{4} 2: 1: 1: 4$} \\
\hline 260 & 30 & 45.3 & 0 & 9.3 & 45.4 & 4.87 & 0 \\
\hline 260 & 60 & 33.6 & 1.6 & 15.5 & 49.4 & 1.97 & 0.10 \\
\hline 260 & 90 & 35.6 & 1.5 & 15.1 & 47.8 & 2.15 & 0.10 \\
\hline 260 & 120 & 35.8 & 2.0 & 15.8 & 46.4 & 1.97 & 0.13 \\
\hline 270 & 120 & 41.0 & 3.8 & 13.3 & 41.9 & 2.40 & 0.29 \\
\hline 280 & 120 & 33.3 & 8.2 & 12.9 & 45.7 & 1.58 & 0.64 \\
\hline \multicolumn{8}{|c|}{$\mathrm{Cu}_{2} \mathrm{ZnSnSe}_{4}$ 2:1.5:1:4 } \\
\hline 280 & 120 & 29.0 & 12.1 & 12.7 & 46.2 & 1.17 & 0.95 \\
\hline \multicolumn{8}{|c|}{$\mathrm{Cu}_{2} \mathrm{ZnSnSe}{ }_{4}$ 2:1.8:1:4 } \\
\hline 280 & 120 & 32.7 & 11.0 & 13.2 & 43.2 & 1.35 & 0.83 \\
\hline Stoich & osition & 25.0 & 12.5 & 12.5 & 50 & 1.00 & 1.00 \\
\hline Optim & tion of SC composition & 22.22 & 14.55 & 13.23 & 50 & $0.80-0.85$ & $1.10-1.2 C$ \\
\hline
\end{tabular}

It was found that with increasing synthesis temperature, the amount of zinc in the samples gradually increases from 3.8 to 8.2 at.\% for temperatures of $270^{\circ} \mathrm{C}$ and $280^{\circ} \mathrm{C}$, respectively. That is, increasing the synthesis temperature promotes to the entry of zinc atoms into the final product. Since the experimentally obtained ratio of the constituent atoms in the material is nonstoichiometric, it can be assumed that the obtained product still consists of several phases.

To obtain a single-phase product during synthesis at a temperature of $280^{\circ} \mathrm{C}$ and a time of 120 min the concentration of zinc in the reaction medium was increased from 1.5 to 1.8 times. At the same time, the content of other components of the compound in the precursor remained unchanged. The results of the X-ray phase analysis showed that the spectra from the samples are similar to the previously obtained spectra (Fig. 4), which are characteristic to single-phase samples.

Page 5/19 
Analysis of the results obtained by the EDAX method showed (Table 1) that the optimal composition for the synthesis of the $\mathrm{Cu}_{2} \mathrm{ZnSnSe}_{4}$ compound is a molar ratio of 2:1.5:1:4. In this case, the formed product was the closest $\left(C_{C u}=29.0\right.$ at. \%, $C_{Z n}=12,1$ at.\%, $C_{S n}=12.7$ at.\%, $C_{S e}=46.2$ at.\%) to the stoichiometric composition $\left(C_{C u}=25.0\right.$ at.\%, $C_{Z n}=12,5$ at.\%, $C_{S n}=12.5$ at.\%, $C_{S e}=50.0$ at.\%). With a further increase in the proportion of zinc in the reaction mixture to 1.8 , there is an increase in the content of copper and tin in the samples to 32.7 at.\% and 13.2 at.\%, respectively, with a simultaneous decrease in the final synthesis product, namely zinc and selenium to 11.0 at.\% and 43.2 at.\%, respectively (Table. 1).

To establish the influence of growth time on the structural and substructural characteristics of $\mathrm{Cu}_{2} \mathrm{ZnSnSe}{ }_{4} \mathrm{NCs}$, we determined the sizes of coherent scattering regions $(L)$, the level of microdeformations $(\varepsilon)$, and the lattice parameters $\left(a, c, c / a V_{\text {unit. }}\right)$. The corresponding calculated values are given in Table 2 . There are also reference values of the crystal lattice constants of the studied compounds. 
Table 2

The structural and microstructural properties of $\mathrm{Cu}_{2} \mathrm{ZnSnSe}{ }_{4} \mathrm{NCs}$ synthesized by different approaches

\begin{tabular}{|c|c|c|c|c|c|c|c|c|c|c|c|}
\hline \multicolumn{2}{|c|}{ Samples } & \multirow{2}{*}{$\begin{array}{l}L_{(112)} \\
\mathrm{nm}\end{array}$} & \multirow{2}{*}{$\begin{array}{l}L_{(204)} \\
\mathrm{nm}\end{array}$} & \multirow{2}{*}{$\begin{array}{l}L_{(312)} \\
\mathrm{nm}\end{array}$} & \multirow{2}{*}{$\begin{array}{l}\varepsilon_{(112)} \\
10^{3}\end{array}$} & \multirow{2}{*}{$\begin{array}{l}\varepsilon_{(204)} \\
10^{3}\end{array}$} & \multirow{2}{*}{$\begin{array}{l}\varepsilon_{(312)} \\
10^{3}\end{array}$} & \multirow{2}{*}{$\begin{array}{l}a_{(112)} \\
a_{U C} \\
n m\end{array}$} & \multirow{2}{*}{$\begin{array}{l}c_{(122)} \\
c_{U C} \\
\mathrm{~nm}\end{array}$} & \multirow{2}{*}{$\begin{array}{l}c_{(122)} / 2 a_{(122)} \\
c_{U d} / 2 a_{U C}\end{array}$} & \multirow{2}{*}{$\begin{array}{l}V_{\text {unit(112) }} \\
V_{\text {unit(UC) }} \\
\mathrm{nm}^{3}\end{array}$} \\
\hline${ }^{\circ}{ }^{\circ} \mathrm{C}$ & $\begin{array}{l}\tau, \text { min., } \\
\text { precursor } \\
\text { composition }\end{array}$ & & & & & & & & & & \\
\hline \multicolumn{12}{|c|}{ NCs synthesized by the first approach } \\
\hline \multirow[t]{2}{*}{240} & 0 & 4.47 & 4.77 & 4.72 & 8.16 & 7.69 & 7.79 & 0.56624 & 1.11545 & 0.9850 & 0.3576 \\
\hline & $2: 1: 1: 4$ & & & & & & & 0.56739 & 1.12621 & 0.99245 & 0.3626 \\
\hline \multirow[t]{2}{*}{240} & 15 & 7.29 & 6.19 & 5.82 & 5.02 & 5.94 & 6.34 & 0.56624 & 1.11545 & 0.9905 & 0.3576 \\
\hline & $2: 1: 1: 4$ & & & & & & & 0.56619 & 1.13345 & 1.0009 & 0.3634 \\
\hline \multirow[t]{2}{*}{240} & 30 & 8.10 & 6.90 & 6.55 & 4.53 & 5.34 & 5.64 & 0.56726 & 1.12134 & 0.9952 & 0.3608 \\
\hline & $2: 1: 1: 4$ & & & & & & & 0.56777 & 1.12839 & 0.9937 & 0.3638 \\
\hline \multirow[t]{2}{*}{240} & 45 & 8.36 & 7.27 & 6.95 & 4.40 & 5.08 & 5.32 & 0.56726 & 1.12134 & 0.9884 & 0.3608 \\
\hline & $2: 1: 1: 4$ & & & & & & & 0.56695 & 1.13165 & 0.9980 & 0.3638 \\
\hline \multirow[t]{2}{*}{240} & 60 & 9.03 & 7.51 & 7.05 & 4.07 & 4.92 & 5.24 & 0.56624 & 1.11545 & 1.0070 & 0.3576 \\
\hline & $2: 1: 1: 4$ & & & & & & & 0.56605 & 1.13298 & 1.0008 & 0.3630 \\
\hline \multicolumn{12}{|c|}{ NCs synthesized by the second approach } \\
\hline \multirow[t]{2}{*}{260} & 120 & 16.54 & 15.08 & 14.32 & 2.27 & 2.50 & 2.64 & 0.56624 & 1.11545 & 0.9849 & 0.3576 \\
\hline & $2: 1: 1: 4$ & & & & & & & 0.56645 & 1.13290 & 1.0000 & 0.3635 \\
\hline \multirow[t]{2}{*}{270} & 120 & 21.17 & 20.99 & 20.91 & 1.77 & 1.82 & 1.84 & 0.56829 & 1.12732 & 0.99185 & 0.3641 \\
\hline & $2: 1: 1: 4$ & & & & & & & 0.56802 & 1.13600 & 0.9999 & 0.3665 \\
\hline \multirow[t]{2}{*}{280} & 120 & 20.22 & 19.39 & 18.68 & 1.85 & 1.96 & 2.05 & 0.56931 & 1.13338 & 0.9954 & 0.3673 \\
\hline & $2: 1: 1: 4$ & & & & & & & 0.56820 & 1.13611 & 0.9997 & 0.3668 \\
\hline \multirow[t]{2}{*}{280} & 120 & 19.61 & 18.54 & 17.68 & 1.90 & 2.05 & 2.16 & 0.57138 & 1.14577 & 1.0026 & 0.3741 \\
\hline & $2: 1.5: 1: 4$ & & & & & & & 0.56925 & 1.13760 & 0.9992 & 0.3686 \\
\hline \multirow[t]{2}{*}{280} & 120 & 24.23 & 22.95 & 21.23 & 1.55 & 1.67 & 1.81 & 0.57138 & 1.14577 & 1.0026 & 0.3741 \\
\hline & $2: 1.8: 1: 4$ & & & & & & & 0.56956 & 1.13741 & 0.9985 & 0.3690 \\
\hline \multicolumn{2}{|c|}{ Reference } & $\begin{array}{l}a=0.5 \\
{[J C P D}\end{array}$ & 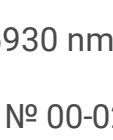 & $\begin{array}{l}=1.13 \\
0575]\end{array}$ & n nm, & $a=0.99$ & $35, V_{\text {KOM }}$ & $0.3673 n$ & & & \\
\hline
\end{tabular}

The lattice parameters of semiconductor materials are a characteristic that is extremely sensitive to the introduction of impurities, changes in stoichiometry, oxidation, so the exact definition of these values allows us to study the relevant processes. Table 2 shows the obtained values of $\mathrm{Cu}_{2} \mathrm{ZnSnSe}_{4} \mathrm{NCs}$ lattice parameters calculated using relations (1) for reflections from the crystallographic plane (112) and the program UnitCell. It was found that the values of the lattice parameters found by two different methods differed quite significantly in magnitude. The general form of the dependences $a, c, c / 2 a, V_{\text {unit }}$ from $T, \tau$ and precursors composition was very similar. Since the results obtained using the UnitCell program are based on the analysis of all reflections presented on the samples diffractograms, they are more accurate. In this regard, only this data will be discussed.

Analysis of the results of diffractometric studies shows that the lattice parameters of the material of nanocrystals synthesized by the first method vary in the following range: $a_{U C}=(0.56605-0.56777) \mathrm{nm}, c_{U C}=(1.12621-1.13345) \mathrm{nm}, c_{U C} / 2 a_{U C}=(0.99245-$ 
1.0009). At the start, with an increase of the synthesis time, the value increases to the maximum $\left(a_{U C}=0.56777 \mathrm{~nm}\right.$, at $\left.\tau=30 \mathrm{~min}\right)$, and then decreases to the minimum $\left(a_{U C}=0.56605 \mathrm{~nm}, \tau=60 \mathrm{~min}\right)$. Closest to the reference data $\left(a_{U C}=0.56930 \mathrm{~nm}\right)$ had material of NCs synthesized at $\tau=45 \mathrm{~min}\left(a_{U C}=0.56695 \mathrm{~nm}\right)$.

At the same time, the value of the lattice parameter $\mathrm{c}$ with an increase in the NCs synthesis time increases, practically reaching at $\tau$ $=60 \mathrm{~min}\left(c_{U C}=1.13298 \mathrm{~nm}\right)$ values typical for stoichiometric materials $\left(c_{U C}=1.13330 \mathrm{~nm}\right)$ [68-70]. A similar increase is observed for the ratio of these quantities $c_{U C} / 2 a_{U c}$, which at synthesis times $\tau=(45-60)$ min begins to exceed the reference data values. Simultaneously calculated unit cell volume of the compound $\left(V_{\text {unit }(U C)}=(0.3626-0.3638) \mathrm{nm}^{3}\right)$ turned out to be less than the reference $\left(V_{\text {unit }(U C)}=0.3673 \mathrm{~nm}^{3}\right)$ overall range of synthesis times.

For NCs synthesized by the second method, there is a tendency to increase such lattice parameters as $a_{U C}, c_{U C}, V_{u n i t(U C)}$ with an increase of the synthesis temperature and zinc content in precursor at same time relationship $c_{U C} / 2 a_{U C}$ decreases (Table 2 ).

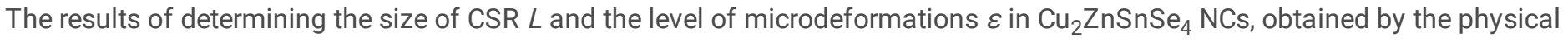
broadening of the diffraction peaks (112), (204), (312) are shown in Table 2.

Analysis of these results shows that with the increasing of the synthesis time, the CSR sizes of $\mathrm{Cu}_{2} \mathrm{ZnSnSe}_{4} \mathrm{NCs}_{\mathrm{n}}$ synthesized by the first method in the [112] direction increases from $4.47 \mathrm{~nm}(\tau=0)$ to $9.03 \mathrm{~nm}$ ( $\tau=60 \mathrm{~min})$. A similar, albeit somewhat smaller, an increase of $L$ occurs in two other directions. [204] and [312]. At the same time with the accuracy of the method form of CSR is close to spherical.

The CSR size of NCs synthesized by the second method turned out to be much larger than the by the first and vary in range $L_{(112)}=$ (16.54-24.23) $\mathrm{nm}$. There was also a tendency for nanocrystals CSR sizes to increase with an increase of the synthesis temperature and the amount of zinc in the precursor. A similar process was observed for $L$ in the directions [204] and [312]. As in the first case, the CSR sizes were close to spherical. It should be noted that the CSR sizes practically coincided with the NCs sizes determined using transmission electron microscopy (Fig. 2). This suggests that nanocrystals usually consist of one single CSR.

The level of microdeformations in NCs synthesized from selenourea in the [112] direction with an increase in the synthesis time, it decreases from $\varepsilon_{(112)}=8.16 \cdot 10^{-3}(\tau=0 \mathrm{~min})$ to $\varepsilon_{(112)}=4.1 \cdot 10^{-3}$ ( $\tau=60 \mathrm{~min}$ ). A similar decrease was observed in other investigated crystallographic directions. (Table 2). The same effect was caused by an increase in temperature and an increase in zinc content in the precursor during the synthesis of NCs by method two. It should be noted that when we use amorphous selenium as the Se source, the resulting NCs had larger CSR sizes and had a significantly (2-4 times) lower level of microdeformations ( $\varepsilon_{(112)}=$ $\left.\left(4.07 \cdot 10^{-3}-8.16 \cdot 10^{-3}\right)\right)$ compared to those obtained using selenourea $\left(\varepsilon_{(112)}=\left(1.55 \cdot 10^{-3}-2.27 \cdot 10^{-3}\right)\right)$. Since both the CSR boundaries and microdeformations in the material are due to the presence of dislocations, increasing $L$ and decreasing $\varepsilon$ should lead to a decrease in the density of dislocations in films, which will subsequently be created using synthesized NCs [71-73].

Figure 5 shows the FTIR spectra from NCs, taken in the mode of full reflection of light at room temperature. FTIR absorption spectra were measured to identify the chemical bonds in the investigated samples [74]. As can be seen from the figure, the absorption bands are observed in the spectra at the following frequencies: $3741 \mathrm{~cm}^{-1}, 3421 \mathrm{~cm}^{-1}, 2558 \mathrm{~cm}^{-1}, 2164 \mathrm{~cm}^{-1}, 2037 \mathrm{~cm}^{-1}, 1979$ $\mathrm{cm}^{-1}, 1647 \mathrm{~cm}^{-1}, 1165 \mathrm{~cm}^{-1}, 1068 \mathrm{~cm}^{-1}$. It should be noted that the $\mathrm{Cu}_{2} \mathrm{ZnSnSe}{ }_{4}$ kesterite phase's active IR oscillations were not detected in the measured range due to their location at lower wavelengths $\left(50-400 \mathrm{~cm}^{-1}\right)[75]$.

Therefore, the primary attention was paid to identifying residues of organic surfactants and solvents used in the synthesis of NCs. As the spectra analysis shows, the absorption bands at $3741 \mathrm{~cm}^{-1}$ and $1647 \mathrm{~cm}^{-1}$ can be associated with the valence vibrations of $\mathrm{O}-\mathrm{H}$ bonds and the $\mathrm{H}$ - $\mathrm{O}$ - $\mathrm{H}$ oscillation group, respectively [76]. The appearance of these bands indicates the presence of water residues in NCs. The peak at a frequency of $1068 \mathrm{~cm}^{-1}$ belongs to the $\mathrm{CO}_{2}$ carbonate group, which was formed in connection with carbon dioxide in the air [77]. At the same time, the band at $2558 \mathrm{~cm}^{-1}$ belong to the S-H oscillation group. The most pronounced absorption bands at the frequencies of $2164 \mathrm{~cm}^{-1}, 2037 \mathrm{~cm}^{-1}, 1979 \mathrm{~cm}^{-1}$, belong to $\mathrm{C}$-H group, due to the use of organic matter in the synthesis of NCs. The peak at $1165 \mathrm{~cm}^{-1}$ is associated with stretched $\mathrm{C}-\mathrm{OH}$ bonds. Thus, the studied samples mainly contain residues of substances used in their synthesis. 


\section{Conclusion}

1. This work proposes a new procedure for the polyol synthesis of $\mathrm{NCs}$ of the $\mathrm{Cu}_{2} \mathrm{ZnSnSe}_{4}$ compound, where amorphous selenium is used as a Se source. The optimal synthesis conditions are selected: its temperature $\left(T=280{ }^{0} \mathrm{C}\right)$, time $(\tau=120 \mathrm{~min})$ and the molar ratio of the components in the precursor (2:1.5:1:4) in which the crystals had a single-phase structure of the kesterite type and the composition $\left(C_{C u}=29.0\right.$ at.\%, $C_{Z n}=12.1$ at.\%, $C_{S n}=12.7$ at.\%, $C_{S e}=46.2$ at.\%) close to stoichiometric. The use of elemental selenium for synthesis made it possible to reduce the cost of obtaining the compound significantly.

2. We compared the structural (phase composition, crystal lattice parameters, unit cell volume) and substructural (CSR sizes, level of microdefromations) properties of $\mathrm{Cu}_{2} \mathrm{ZnSnSe}{ }_{4} \mathrm{NCs}$, obtained by synthesis using as a source of Se, selenourea, which is traditional in such cases (approach 1), and amorphous selenium (approach 2).

3. Using the UnitCell program and the position of the diffraction reflection from the [112] crystallographic plane, we determined the lattice parameters of the synthesized crystals. It was found that although the values of the unit cell constants of the material found by two different methods differed significantly in magnitude, the general form of the dependences of $a, c, c / 2 a, V_{u n i t}$ on $T, \tau$ and the composition of precursors was similar. It was shown that the lattice parameters of NCs synthesized by the first method vary in the range: $a_{U C}=(0.56605-0.56777) \mathrm{nm}, c_{U C}=(1.12621-1.13345) \mathrm{nm}, c_{U C} / 2 a_{U C}=(0.99245-1.0009)$. The closest to reference data $a_{U C}=0.56930 \mathrm{~nm}$ was found in the NCs synthesized at $\tau=45 \mathrm{~min}$. For NCs synthesized by the second method, a tendency for $a, c, V_{\text {unit }}$ to increase with an increase in the synthesis temperature and zinc content in the precursor was observed. At the same time, the ratio $c / 2 a$ decreases. The results obtained correlate well with the data given in the reference literature.

4. It was found that the size of NCs synthesized using elemental selenium as a precursor component $(D=(18-30) \mathrm{nm})$ and CSR $\left.L_{(112)}=(16.54-24.23) \mathrm{nm}\right)$ were significantly more than when using selenourea, $D=(5-12) \mathrm{nm}, L_{(112)}=(4.47-9.03) \mathrm{nm}$. At the same time, these sizes increased with an increase of the synthesis temperature and zinc content in the precursor. A similar increase in the CSR sizes was observed in NCs synthesized with the use of selenourea with an increase in the time of their synthesis. Both in the first and the second case, the crystals CSR had a shape close to spherical.

5. It was shown that when using amorphous selenium as a Se source, the obtained NCs had a significantly (2-4 times) lower level of microdeformations $\left(\varepsilon_{(112)}=\left(4.07 \cdot 10^{-3}-8.16 \cdot 10^{-3}\right)\right)$ compared to those obtained using selenourea $\left(\varepsilon_{(112)}=1.55 \cdot 10-3\right.$ 2.27-10-3), thus films based on them will contain less dislocation centers which are the effective recombination centers of charge carriers.

6. Synthesized $\mathrm{Cu}_{2} \mathrm{ZnSnSe}_{4} \mathrm{NCs}$ dispersed in an environmentally friendly mixture of water, glycol, alcohol, polyvinylpyrrolidone can be used for 2D and 3D printing of films of a four-component compound, used as absorbers of third-generation solar cells, active layers of thermogenerators, and other electronic devices.

\section{Declarations}

\section{Compliance with ethical standards}

Conflict of interest The authors declare no competing interests and all co-authors have approved the contents of this manuscript and submission.

\section{Acknowledgment}

The research was performed under the financial support of the Ministry of Education and Science of Ukraine (0119U100398). This work was also supported by the National Research Foundation of Ukraine (project registration number: 2020.02 / 0313).

\section{References}

[1] A.H. Espera, J.R.C. Dizon, Q. Chen, 3D-printing and advanced manufacturing for electronics, Prog. Addit. Manuf. 4 (2019) 245267. https://doi.org/10.1007/s40964-019-00077-7. 
[2] R. Yang, J. Zhou, C. Yang, L. Qiu, H.-M. Cheng, Recent progress in 3d printing of 2d material-based macrostructures, Adv. Mater. Technol. 5 (2020) 1901066. https://doi.org/10.1002/admt.201901066.

[3] Z. Zhu, D.W.H. Ng, H.S. Park, 3D-printed multifunctional materials enabled by artificial-intelligence-assisted fabrication technologies, Nat. Rev. Mater. (2020) 6 (1), 27-47. https://doi.org/10.1038/s41578-020-00235-2.

[4] H. Yang, W.R. Leow, X. Chen, Printing of flexible electronic devices, Sm. Meth. 2 (2018) 1700259.

https://doi.org/10.1002/smtd.201700259.

[5] B.S. Cook, B. Tehrani, J.R. Cooper, S. Kim, M. Tentzeris, Integrated printing for 2D/3D flexible organic electronic devices, Mat. Man. Appl. (2015) 199-216. https://doi.org/10.1016/B978-1-78242-035-4.00008-7.

[6] Q. Huang, Y. Zhu, Printing conductive nanomaterials for flexible and stretchable electronics: a review of materials, Adv. Mater. Technol. 4 (2019) 1800546. https://doi.org/10.1002/admt.201800546.

[7] W. Zhu, S. Park, M. Yogeesh, D. Akinwande, Advancements in 2D flexible nanoelectronics: from material perspectives to RF applications, Flexible Printed Electron. 2 (2017) 043001. https://doi.org/10.1088/2058-8585/aa84a4.

[8] K.S. Kumar, P.Y. Chen, H. Ren, A review of printable flexible and stretchable tactile sensors, Res. (2019) 3018568.

https://doi.org/10.34133/2019/3018568.

[9] V. Chi-Fung Li, X. Kuang, C.M. Hamel, D. Roach, Y. Deng, H. Jerry Qi, Cellulose nanocrystals support material for 3D printing complexly shaped structures via multi-materials-multi-methods printing, Addit. Manuf. 28 (2019) 14.

https://doi.org/10.1016/j.addma.2019.04.013.

[10] G. Siqueira, D. Kokkinis, R. Libanori, M. K. Hausmann, A. S. Gladman, A. Neels, P. Tingaut, T. Zimmermann, J. A. Lewis, A. R. Studart, Cellulose nanocrystal inks for 3d printing of textured cellular architectures, Adv. Funct. Mater. 27 (2017) 1604619. https://doi.org/10.1002/adfm.201604619.

[11] I.J. Fernandes, A.F. Aroche, A. Schuck, Silver nanoparticle conductive inks: synthesis, characterization, and fabrication of inkjetprinted flexible electrodes, Sci Rep 10 (2020) 8878. https://doi.org/10.1038/s41598-020-65698-3.

[12] L. Nayak, S. Mohanty, S. Nayak, A. Ramadoss, A review on inkjet printing of nanoparticle ink for flexible electronics, J. Mater. Chem. 29 (2019) C7. https://doi.org/10.1039/C9TC01630A.

[13] B. Begines, A. Alcudia, R. Aguilera-Velazquez, Design of highly stabilized nanocomposite inks based on biodegradable polymermatrix and gold nanoparticles for inkjet printing, Sci Rep. 9 (2019) 16097. https://doi.org/10.1038/s41598-019-52314-2.

[14] T. Jie, Z. Jiumeng, D. Ting, X. Xin, D. Xianming, C. Shaochen, L. Jinlu, C. Yuwen, L. Xuan, X. Meimei, L. Yi, Hao Cheng, M. Jian, Ludwig Cardon, G. Maling, W. Yuquan, Rapid 3D printing of functional nanoparticle-enhanced conduits for effective nerve repair, Acta Biomater. 90 (2019) 49-59. https://doi.org/10.1016/j.actbio.2019.03.047.

[15] C. Liu, N. Huang, F. Xu, J Tong, Z. Chen, X. Gui, Y. Fu, C. Lao, 3D printing technologies for flexible tactile sensors toward wearable electronics and electronic skin, Polym. 10 (2018) 629. https://doi.org/10.3390/polym10060629.

[16] T.E. Glier, L. Akinsinde, M. Paufler, Functional printing of conductive silver-nanowire photopolymer composites, Sci Rep 9 (2019) 6465. https://doi.org/10.1038/s41598-019-42841-3.

[17] Y. Liu, Y. Xu, R. Avila, C. Liu, Z. Xie, L. Wang, X. Yu, 3D printed microstructures for flexible electronic devices, Nanotechol. 30 (2019) 41400. https://doi.org/10.1088/1361-6528/ab2d5d.

[18] J. Hoerber, J. Glasschroeder, M. Pfeffer, J. Schilp, M. Zaeh, J. Franke, Approaches for additive manufacturing of 3d electronic applications, Proc. CIRP 17 (2014) 806-811. https://doi.org/10.1016/j.procir.2014.01.090.

[19] Y. Dong, C. Bao, W. Soo Kim, Sustainable additive manufacturing of printed circuit boards, Fut. Energy 2 (2018) 579-582.

https://doi.org/10.1016/j.joule.2018.03.015.

Page 10/19 
[20] J.J. Cabrera-López, M.F. García-Arrunátegui, P. Neuta-Arciniegas, O. Campo, J. Velasco-Medina, PCB-3D-Printed, reliable and reusable wells for impedance spectroscopy of aqueous solutions, J. Phys. Conf. Ser. 1272 (2019) 012017.

https://doi.org/10.1088/1742-6596/1272/1/012017.

[21] H. W. Tan, J. An, C. K. Chua, T. Tran, Metallic nanoparticle inks for 3D printing of electronics, Adv. Electron. Mater. 5 (2019) 1800831. https://doi.org/10.1002/aelm.201800831.

[22] S. Ganesan, S. Mehta, D. Gupta, Fully printed organic solar cells - a review of techniques, challenges, and their solutions, OptoElectron. Rev. 27 (2019) 298-320. https://doi.org/10.1016/j.opelre.2019.09.002.

[23] S. K. Karunakaran, A. G. Manohari, W. G. Yang, S. Khanib, X. Lin, G. Yang, Recent progress in inkjet-printed solar cells, J. Mater. Chem. A. 7 (2019) 7 (23), 13873-13902. https://doi.org/10.1039/C9TA03155C.

[24] J. Peng, I. Witting, N. Geisendorfer, 3D extruded composite thermoelectric threads for flexible energy harvesting, Nat. Commun. 10 (2019) 5590. https://doi.org/10.1038/s41467-019-13461-2.

[25] F. Kim, B. Kwon, Y. Eom, J.E. Lee, S. Park, S. Jo, S.H. Park, B.S. Kim, H.J. Im, M.H. Lee, T.S. Min, K.T. Kim, H.G. Chae, W.P. King, J.S. Son, 3D printing of shape-conformable thermoelectric materials using all-inorganic $\mathrm{Bi}_{2} \mathrm{Te}_{3}$-based inks, Nat. Energy (2018) 3(4) 301-309. https://doi.org/10.1038/s41560-017-0071-2.

[26] M.R. Burton, S. Mehraban, D. Beynon, J. Mc Gettrick, T. Watson, N.P. Lavery, M.J. Carnie, 3D printed SnSe thermoelectric generators with high figure of merit, Adv. Energy Mater 9 (2019) 1900201. https://doi.org/10.1002/aenm.201900201.

[27] N. Bandari, J. Dargahi, M. Packirisamy, Tactile Sensors for Minimally Invasive Surgery: A Review of the State-of-the-Art, Applications, and Perspectives, Access (2020) 7682-7708. https://doi.org/10.1109/ACCESS.2019.2962636.

[28] Y. Ni, R. Ji, K. Long, T. Bu, K. Chen, S. Zhuang, A review of 3D printed sensors, Appl. Spectrosc. Rev. 52 (2017) 623-652. https://doi.org/10.1080/05704928.2017.1287082.

[29] M. R. Khosravani, T. Reinicke, 3D-printed sensors: Current progress and future challenges, Sens. Actuators 305 (2020) 111916. https://doi.org/10.1016/j.sna.2020.111916.

[30] Z. Minxiang, Z. Yanliang, Colloidal nanoparticle inks for printing functional devices: emerging trends and future prospects, J. Mater. Chem. A 41 (2019) 9. https://doi.org/10.1039/C9TA07552F.

[31] S. Hwan, J. Chung, N. Hotz, K. Hyun, C. Grigoropoulos, Metal nanoparticle direct inkjet printing for low-temperature 3D micro metal structure fabrication, J. Micromech. Microeng. 20 (2010) 125010. https://doi.org/10.1088/0960-1317/20/12/125010

[32] N. Honglong, T. Ruiqiang, Y. Rihui, C. Jianqiu, Y. Caigui, Z. Yicong, C. Wei, Z. Zhennan, P. Junbiao, S. Yongsheng, A review on green and flexible silver nano-ink for inkjet printing, Mater. Rep. 32 (2018) 2959-2968. https://doi.org/10.11896/j.issn.1005023X.2018.17.009.

[33] S. Giraldo, Z. Jehl, M. Placidi, V. Izquierdo-roca, A. Perez-rodriguez, E. Saucedo, Progress and perspectives of thin film kesterite photovoltaic technology: a critical review, Adv. Mater. 31 (2019) 1806692. https://doi.org/10.1002/adma.201806692.

[34] Liu, X., Feng, Y., Cui, H., Liu, F., Hao, X., Conibeer, G., Mitzi, D. B., and Green, M., The current status and future prospects of kesterite solar cells: a brief review, Prog. Photovolt: Res. 24 (2016) 879-898. https://doi:10.1002/pip.2741.

[35] A.S. Nazligul, M. Wang, K.L. Choy, Recent development in earth-abundant kesterite Materials and their applications, Sustain. 12 (2020) 5138. https://doi.org/10.3390/su12125138.

[36] P. Krishan, S. Pawan, B. Abhishikta, B. T. Khem, Current challenges and future prospects for a highly efficient (>20\%) kesterite CZTS solar cell: A review, Sol. Energy Mater. Sol. Cells 196 (2019) 138. https://doi.org/10.1016/j.solmat.2019.03.001.

[37] M. Ravindiran, C. Praveenkumar, Status review and the future prospects of CZTS based solar cell - A novel approach on the device structure and material modeling for CZTS based photovoltaic device, Renewable Sustainable Energy Rev. 94 (2018) 317.

Page 11/19 
https://doi.org/10.1016/j.rser.2018.06.008.

[38] T. Ratz, G. Brammertz, R. Caballero, M. León, S. Canulescu, J. Schou, L. Gütay, D. Pareek, T. Taskesen, K. Teoman, Dae-Hwan, J. K. Kang, C. Malerba, A. Redinger, E. Saucedo, B. Shin, H. Tampo, K. Timmo, N. D. Nguyen, B. Vermang, Physical routes for the synthesis of kesterite, J. Phys.: Energy 1 (2019) 42003. https://doi.org/10.1088/2515-7655/ab281c.

[39] Z. Shi, D. Attygalle, A.H. Jayatissa, Kesterite-based next generation high performance thin film solar cell: current progress and future prospects, J Mater Sci: Mat. Elec. 28 (2017) 2290. https://doi.org/10.1007/s10854-016-5753-1.

[40] F. Martinho, S. Marino, M. Espindola, A. Hajijafarassar, F. Stulen, S. Grini, M. Döbeli, M. Gansukh, S. Engberg, E. Stamate, L. Vines, J. Schou, O. Hansen, S. Canulescu, Persistent double-layer formation in kesterite solar cells: a critical review, ACS Appl. Mater. Interfaces 12 (2020) 39405. https://doi.org/10.1021/acsami.0c10068.

[41] M.A. Green, E.D. Dunlop, J. Hohl-Ebinger, M. Yoshita, N. Kopidakis, X. Hao, Solar cell efficiency tables (version 56), Prog. Photovolt. Res. Appl. 28 (2020) 629. https://doi.org/10.1002/pip.3303.

[42] T. Gokmen, O. Gunawan, T. Todorov, D.B. Mitzi, Band tailing and efficiency limitation in kesterite solar cells, Appl. Phys. Lett. 103 (2013) 103506-103506. https://doi.org/10.1063/1.4820250.

[43] M. Suryawanshi, G. Agawane, S. M. Bhosale, S.W. Shin, P. Patil, K. Jeong-Hoon, A. Moholkar, CZTS based thin film solar cells: A status review, Mat. Techn., 28 (2013) 98-109. https://doi.org/10.1179/1753555712Y.0000000038.

[44] J. Wang, J. Hu, Y. Guo, Wurtzite $\mathrm{Cu}_{2} \mathrm{ZnSnSe}{ }_{4}$ nanocrystals for high-performance organic-inorganic hybrid photodetectors, NPG Asia Mater. 4 (2012) e2. https://doi.org/10.1038/am.2012.2.

[45] C. Leidholm, C. Hotz, A. Breeze, C. Sunderland, W. Ki, D. Zehnder, Final report: sintered CZTS nanoparticle solar cells on metal foil, NREL/SR-5200-56501 (2012).

[46] M. Huang, H.S. Zheng, A.X. Wei, Synthesis of $\mathrm{Cu}_{2} \mathrm{ZnSn}\left(\mathrm{S}_{\mathrm{x}} \mathrm{Se}_{1-\mathrm{x}}\right)_{4}$ thin films directly on transparent conductive glass substrates by solvothermal method, J Mater Sci: Mater Electron 29 (2018) 8049-8056. https://doi.org/10.1007/s10854-018-8811-z.

[47] P. Mou, N.R. Mathews, R. Silva Gonzalez, X. Mathew, Synthesis of $\mathrm{Cu}_{2} \mathrm{ZnSnS}_{4}$ nanocrystals by solvothermal method, Thin Solid Films 535 (2013) 78. https://doi.org/10.1016/j.tsf.2012.11.043.

[48] Y. Li, Q. Han, T. W. Kim, W. Shi, Synthesis of wurtzite-zincblende $\mathrm{Cu}_{2} \mathrm{ZnSnS}_{4}$ and $\mathrm{Cu}_{2} \mathrm{ZnSnSe}_{4}$ nanocrystals: Insight into the structural selection of quaternary and ternary compounds influenced by binary nuclei, Nanoscale 6 (2014) 3777-85. https://doi.org/10.1039/c3nr05358j.

[49] R. Chalapathy, S. Das, J. S. Ma, J. C. Sung, C. H. Lu, Characterization of $\mathrm{Cu}_{2} \mathrm{ZnSnSe}_{4}$ (CZTSe) nanoparticles synthesized via solvothermal method for solar cell applications, J. Mater. Sci.: Mater. Electron. 26 (2015) 7673. https://doi.org/10.1007/s10854-0153408-2.

[50] W. Lu, S. Yiling, X. Yong, Synthesis of $\mathrm{Cu}_{2} \mathrm{ZnSnSe}_{4}$ nanoparticles via solvothermal route, 2016 4th International Conference on Advanced Materials and Information Technology Processing (AMITP 2016). https://doi.org/10.2991/amitp-16.2016.99.

[51] K. Liu, N. Ji, L. Shi, H. Liu, The phase and morphology of $\mathrm{Cu}_{2} \mathrm{ZnSnSe}_{4}$ nanopowders by hydrothermal method, J. Nanomater. (2014) 1-5. https://doi.org/10.1155/2014/910639.

[52] C. Jin, P. Ramasamy, J. Kim, Facile hot-injection synthesis of stoichiometric $\mathrm{Cu}_{2} \mathrm{ZnSnSe}{ }_{4}$ nanocrystals using bis(triethylsilyl) selenide, Dalton Trans. (Cambridge, England). 25 (2014) 43. https://doi.org/10.1039/c4dt00688g.

[53] M. Ibáñez, T. Berestok, O. Dobrozhan, Phosphonic acids aid composition adjustment in the synthesis of $\mathrm{Cu}_{2+x} \mathrm{Zn}_{1-x} \mathrm{SnSe}_{4-}$ y nanoparticles, J. Nanopart. Res. 18 (2016) 226. https://doi.org/10.1007/s11051-016-3545-4. 
[54] C. Wang, S. Shei, and S. Chang, Synthesis and characterization of CZTSe nanoinks using polyetheramine as solvent, Opt. Mater. Express. 4 (2014) 1593-1600. https://doi.org/10.1364/OME.4.001593.

[55] C. Wang, S. Shei and S. Chang, Effect of solvent chelating on crystal growth mechanism of CZTSe nanoink in polyetheramine, IEEE Transactions on Nanotechnology 14 (2015) 896. https://doi.org/10.1109/TNANO.2015.2460257.

[56] O. Dobrozhan, M. Baláž, S. Vorobiov, P. Baláž, A. Opanasyuk, Morphological, structural, optical properties and chemical composition of flexible $\mathrm{Cu}_{2} \mathrm{ZnSnS}_{4}$ thin films obtained by ink-jet printing of polyol-mediated nanocrystals, J. Alloys Compd. 842 (2020) 155883. https://doi.org/10.1016/j.jallcom.2020.155883.

[57] S. Kakherskyi, O. Dobrozhan, R. Pshenychnyi, D. Kurbatov, N. Opanasyuk, $\mathrm{Cu}_{2} \mathrm{ZnSnS}_{4}, \mathrm{Cu}_{2} \mathrm{ZnSnSe}_{4}$ nanocrystals as absorbers in 3rd generation solar cells, 2020 IEEE 40th International Conference on Electronics and Nanotechnology (ELNANO). https://doi.org/10.1109/ELNAN050318.2020.9088910.

[58] P. Baláž, M. Hegedus, M. Baláž, O. A. Dobrozhan. Photovoltaic materials: $\mathrm{Cu}_{2} Z_{n S n S}$ (CZTS) nanocrystals synthesized via industrially scalable, green, one-step mechanochemical process, Prog. Photovolt. Res Appl. 27 (2019) 798. https://doi.org/10.1002/pip.3152.

[59] Substructural investigations, Raman and FTIR spectroscopies of nanocrystalline ZnO films deposited by pulsed spray pyrolysis / O. Dobrozhan, A. Opanasyuk, M. Kolesnyk, M. Demydenko, H. Cheong // Phys. Status Solidi A - 2015. - V. 1-7. - P. $2915-2921$. https:// https://doi.org/10.1002/pssa.201532324.

[60] O.A. Dobrozhan, P.S. Danylchenko, D.I. Kurbatov, N.M. Opanasyuk, A.S. Opanasyuk. Structural properties of $\mathrm{Cu}_{2} \mathrm{ZnSnS}_{4}$ thin films produced by nanoink spraying process, Conference: 2017 IEEE 7th International Conference Nanomaterials: Application \& Properties (NAP) (2017) 02NTF07-1-02NTF07-4. https://doi.org/10.1109/NAP.2017.8190368.

[61] G. Chen, C. Yuan, J. Liu, Y. Deng, G. Jiang, W. Liu, C. Zhu, Low cost preparation of Cu2ZnSnS4 and Cu2ZnSn( $\left.\mathrm{S}_{x} \mathrm{Se}_{1-\mathrm{x}}\right) 4$ from binary sulfide nanoparticles for solar cell application, J. of Pow. Sour. 262 (2014) 201-206. https://doi.org/10.1016/j.jpowsour.2014.03.075.

[62] C. Ritchie, A. S. R. Chesman, J. Jasieniak, P. Mulvaney, Aqueous synthesis of $\mathrm{Cu}_{2} \mathrm{ZnSnSe}{ }_{4}$ nanocrystals, Chem. Mater. 31(6) (2019) 2138. https://doi.org/10.1021/acs.chemmater.9b00100.

[63] Y. Li, Q. Han, T. Kim,W. Shi, Synthesis of wurtzite-zincblende Cu2ZnSnS4 and Cu2ZnSnSe4 nanocrystals: insight into the structural selection of quaternary and ternary compounds influenced by binary nuclei (2014) Nanosc. 6(7), 3777. https://doi.org/10.1039/c3nr05358j

[64] International Centre for Diffraction Data, Selected power diffraction data for education and training (search manual and data cards) Pennsylvania. https://doi.org/10.6028/jres.106.052.

[65] O. Dobrozhan, V. Loboda, Ya. Znamenshchykov, A. Opanasyuk, H. Cheong, Structural and optical properties of $\mathrm{Cu}_{2} \mathrm{ZnSnS}_{4}$ films obtained by pulsed spray pyrolysis, J. Nano- Electron. Phys. 9 (2017):01028-1-01028-7. https://doi.org/10.21272/jnep.9(1).01028.

[66] O. Dobrozhan, O. Diachenko, M. Kolesnyk, A. Stepanenko, S. Vorobiov, P. Baláž, S. Plotnikov, A. Opanasyuk. Morphological, structural and optical properties of Mg-doped ZnO nanocrystals synthesized using polyol process, Materials Science in Semiconductor Processing. 102 (2019) 104595. https://doi.org/10.1016/j.mssp.2019.104595.

[67] V. Kosyak, A. Voznyi, P. Onufrijevs, L. Grase, J. Vecstaudža, A. Opanasyuk, A. Medvids, G. Mezinskis. Laser induced SnS ${ }_{2}-S_{S} S$ phase transition and surface modification in $\mathrm{SnS}_{2}$ thin films, Journal of Alloys and Compounds. 688 (2016) 130-139.

https://doi.org/10.1016/j.jallcom.2016.07.103

[68] V. Kosyak, Y. Znamenshchykov, A. Čerškus, E. Dauksta, Y. Gnatenko, L. Grase, J. Vecstaudza, A. Medvids, A. Opanasyuk, G. Mezinskis. Composition dependence of structural and optical properties of $\mathrm{Cd}_{1-\mathrm{x}} \mathrm{Zn}_{\mathrm{x}}$ Te thick films obtained by the close-spaced sublimation, Journal of Alloys and Compounds. 682 (2016) 543-551. https://doi.org/10.1016/j.jallcom.2016.05.065.

Page 13/19 
[69] S. Ji, T. Shi, X. Qiu, A route to phase controllable $\mathrm{Cu}_{2} \mathrm{ZnSn}\left(\mathrm{S}_{1-x} \mathrm{Se}_{\mathrm{x}}\right)$ nanocrystals with tunable energy bands, Sci. Rep. 3 (2013) 2733. https://doi.org/10.1038/srep02733.

[70] S.A. Vanalakar, G.L. Agawane, A.S. Kamble, The green hydrothermal synthesis of nanostructured $\mathrm{Cu}_{2} \mathrm{ZnSnSe}{ }_{4}$ as solar cell material and study of their structural, optical and morphological properties, Appl. Phys. A 123 (2017) 782. https://doi.org/10.1007/s00339-017-1407-2.

[71] Y. Yawei, Q. Wenxiu, Z. Xinyu, Y. Xingtian, X. Yonglei, Q. Meidan, Z. Hongyang, D. Yaping, High-quality $\mathrm{Cu}_{2} \mathrm{ZnSnS}_{4}$ and $\mathrm{Cu}_{2} \mathrm{ZnSnSe}_{4}$ nanocrystals hybrid with $\mathrm{ZnO}$ and $\mathrm{NaYF}_{4}$ : Yb, Tm as efficient photocatalytic sensitizers, Appl. Catal. B 200 (2017) 402. https://doi.org/10.1016/j.apcatb.2016.07.022.

[72] Y. Cao, C. Wang, J. Hu, Solvothermal synthesis and characterization of quaternary $\mathrm{Cu}_{2} \mathrm{ZnSnSe} \mathrm{H}_{4}$ nanocrystals, Adv. Mater. Res. 347-353 (2011) 848-851. https://doi.org/10.4028/www.scientific.net/AMR.347-353.848.

[73] T. Wang, Q. Chen, J. Chen, F. Zhou, Z. Jia, X. Dou, S. Zhuang, Synthesis and characterization of $\mathrm{Cu}_{2} \mathrm{ZnSnSe}_{4}$ nanocrystals prepared by one pot route, Cryst. Res. Technol. 49 (2014) 808. https://doi.org/10.1002/crat.201400167.

[74] S.-H. Hsiao, Y.-T. Chou, Synthesis and electrochromic properties of aromatic polyimides bearing pendent triphenylamine units, Polymer 55 (2014) 2411-2421. https://doi.org/10.1016/j.polymer.2014.03.031.

[75] M. Himmrich, H. Haeuseler, Far infrared studies on stannite and wurtz stannite type compounds, Spectrochim. Acta 47 (1991) 933-942. https://doi.org/10.1016/0584-8539(91)80283-0.

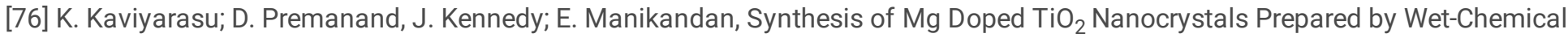
Method: Optical and Microscopic Studies, Int. J. Nanosci. (2013) 12 (5) 1-6. https://doi.org/10.1142/S0219581X13500336.

[77] Mohammad Shiri, H. Aghazadeh, M. Synthesis, Characterization and Electrochemical Properties of Capsule-Like NiO Nanoparticles. J. Electrochem. Soc. 2012, 159 (6), E132-E138. https://doi.org/10.1149/2.106206jes.

\section{Figures}




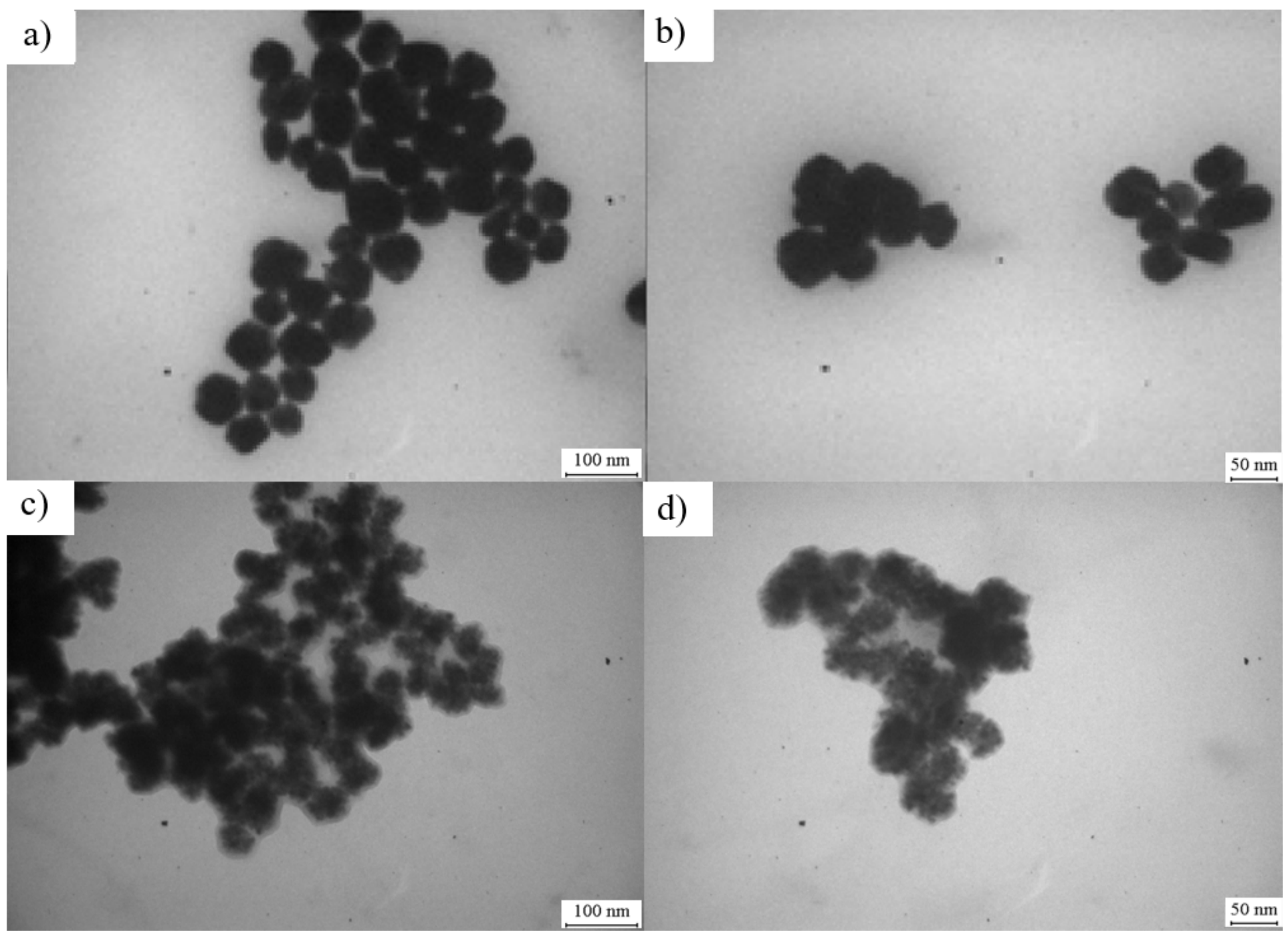

\section{Figure 1}

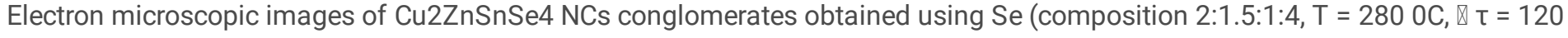
$\min )(\mathrm{a}, \mathrm{b})$ and $(\mathrm{NH} 2) 2 \mathrm{CSe}$ (composition 2:1:1:4, T= $240 \mathrm{oC}, \mathrm{\tau}=30 \mathrm{~min})(\mathrm{c}, \mathrm{d})$ 


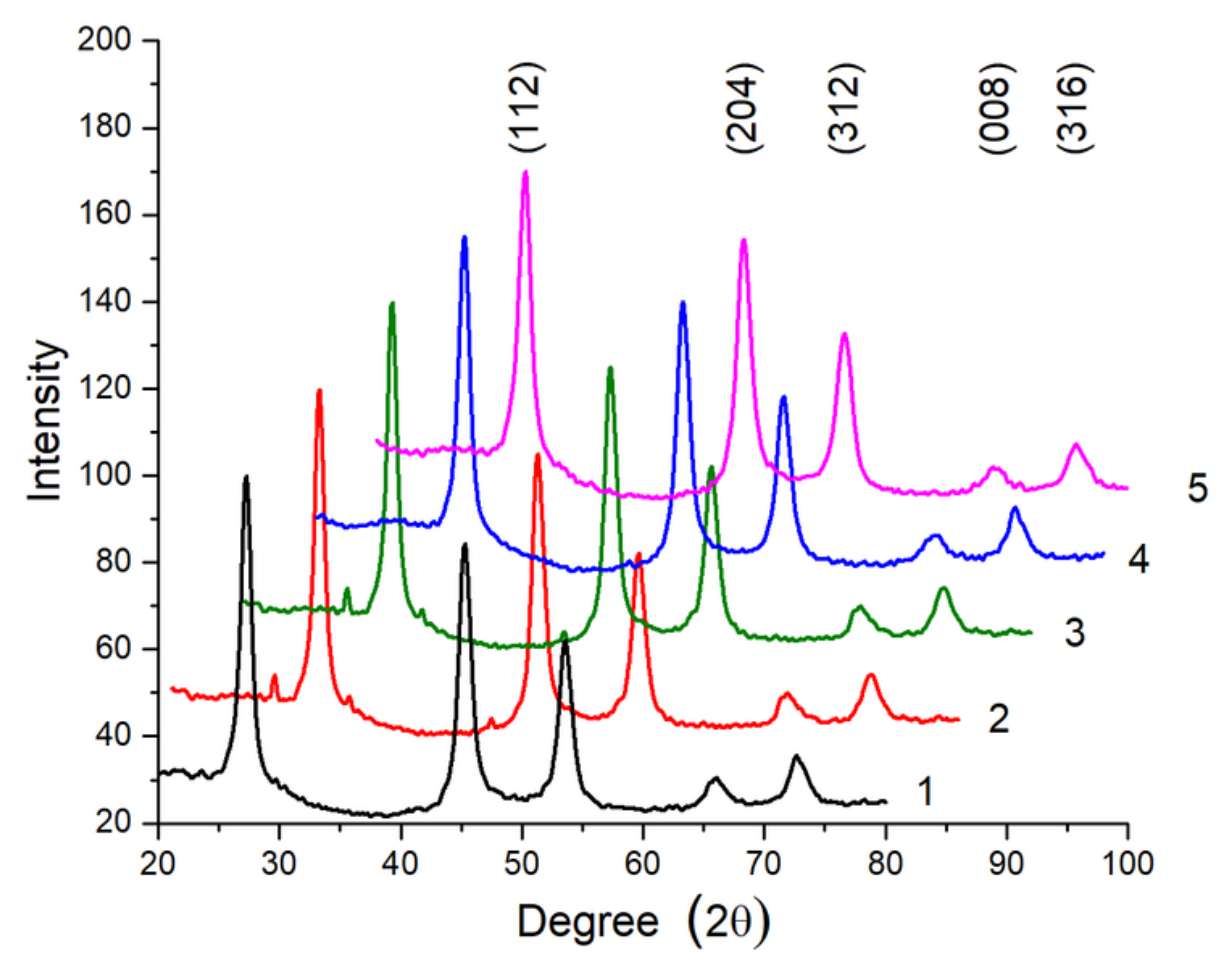

Figure 2

Diffractograms of Cu2ZnSnSe4 NCs synthesized using (NH2)2CSe at T= 240 oC for a time $\tau$, min: 0 (1), 15 (2), 30 (3), 45 (4), 60 (5) 

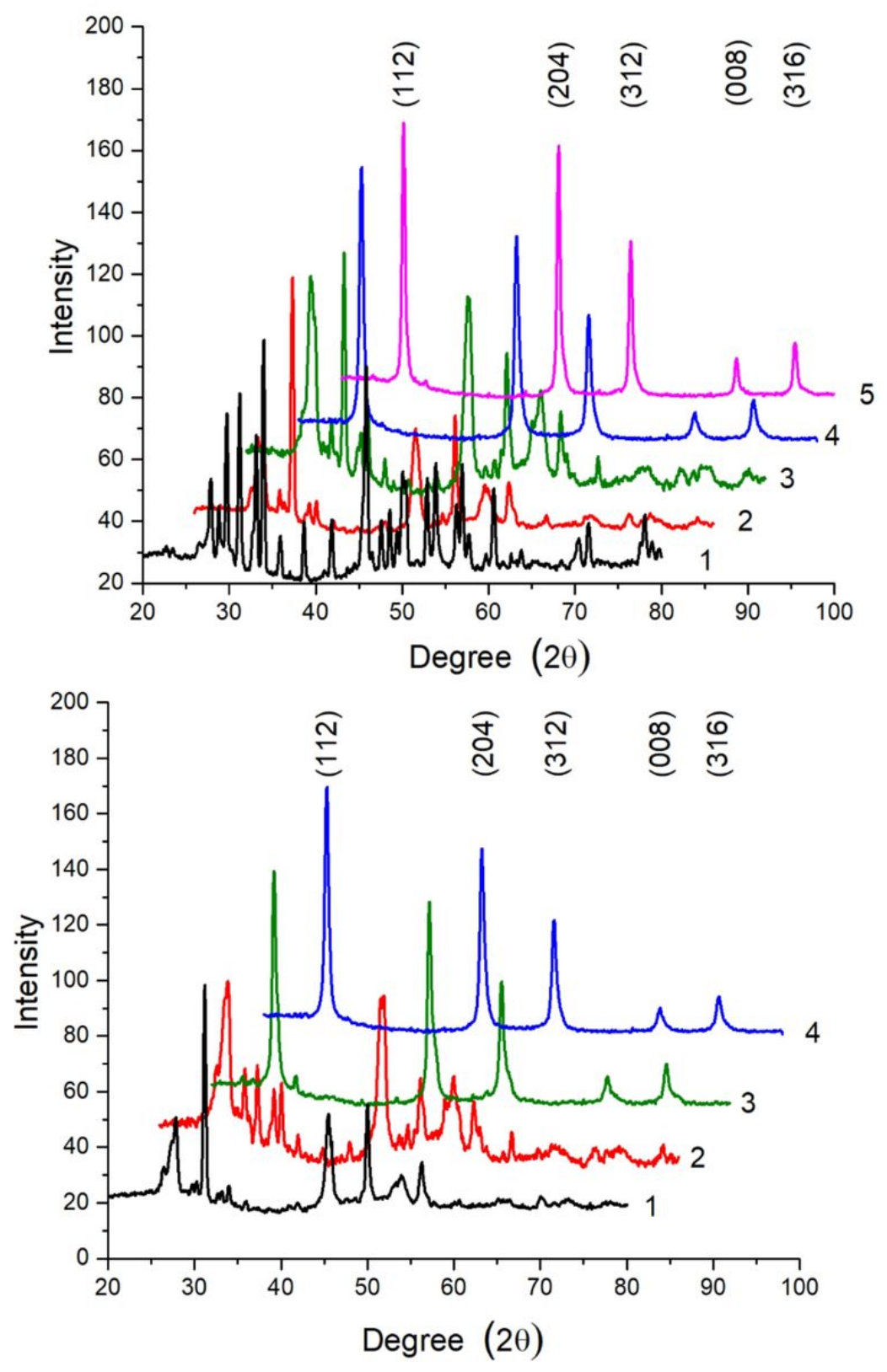

Figure 3

Diffractograms of Cu2ZnSnSe4 NCs synthesized using elemental selenium for time $\tau=120$ min at different temperatures $\mathrm{T}^{\circ} \mathrm{C}$ : 220 (1), 240 (2), 250 (3), 260 (4), 270 (5) 280 (6) (a); at temperature $T=260{ }^{\circ} \mathrm{C}$ for a time t, min: 30 (1), 60 (2), 90 (3), 120 (4) (b) 


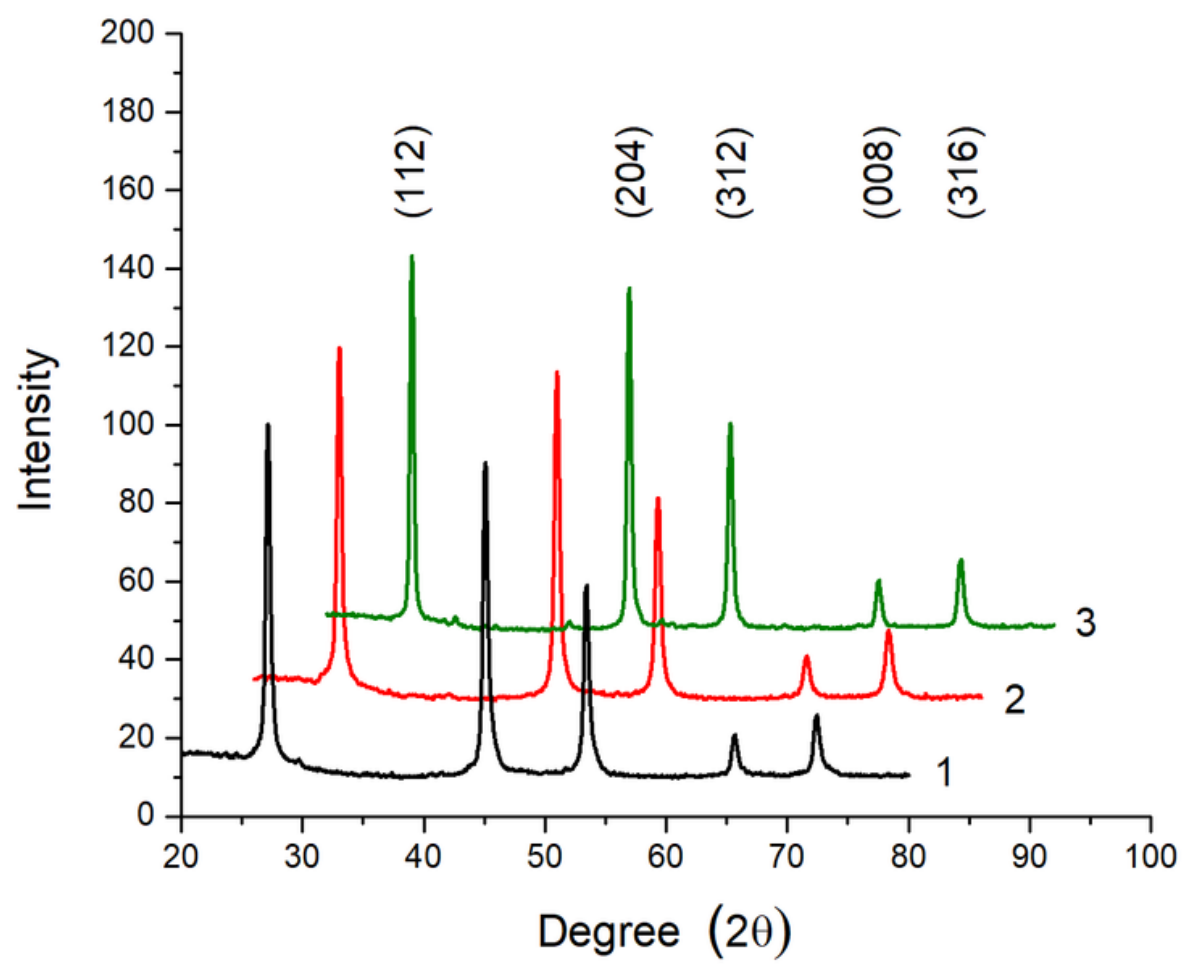

Figure 4

Diffractograms of Cu2ZnSnSe4 NCs synthesized at $\mathrm{T}=280^{\circ} \mathrm{C}, \tau=120 \mathrm{~min}$ for non-stoichiometric precursors 2:1:1:4 (1), 2:1.5:1:4 (2), 2:1.8:1:4 (3)

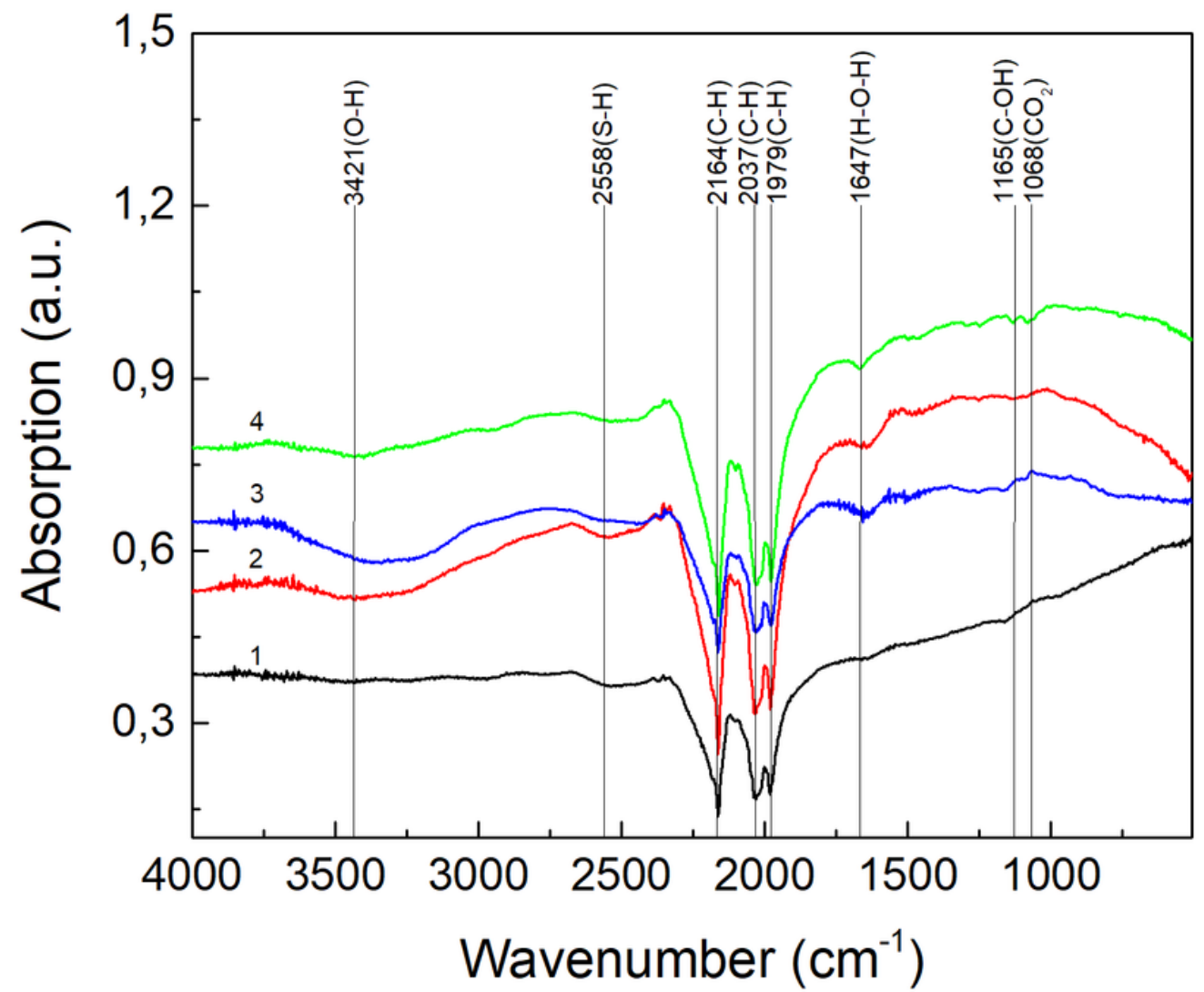

Figure 5 
FTIR spectra of Cu2ZnSnSe4 NCs from $500 \mathrm{~cm}-1$ to $4000 \mathrm{~cm}-1 . T=260^{\circ} \mathrm{C}, \tau=120 \mathrm{~min}$, selenium source - elemental Se, precursor composition - 2:1:1:4 (1); $\mathrm{T}=280^{\circ} \mathrm{C}, \tau=120 \mathrm{~min}, \mathrm{Se}, 2: 1.5: 1: 4(2) ; \mathrm{T}=280^{\circ} \mathrm{C}, \tau=120 \mathrm{~min}, \mathrm{Se}, 2: 1.8: 1: 4(3) ; \mathrm{T}=240{ }^{\circ} \mathrm{C}, \tau=30 \mathrm{~min}$, $(\mathrm{NH} 2) 2 \mathrm{CSe} ; 2: 1: 1: 4(4)$ 